\title{
Dynamic mechanical properties of Polyurethane Shape Memory Polymer Composites (SMPC) with different volume fractions of chopped strand mat glass fiber
}

\author{
Nor Hanim Khiyon ${ }^{1 *}$, Azerai Ali Rahman ${ }^{1}$, Mohd Fadzil Arshad ${ }^{1}$, Mohd \\ Khairul Kamarudin ${ }^{1}$, Sajith Totthatil A. Rahman ${ }^{1}$ \\ ${ }^{1}$ Faculty of Civil Engineering, Universiti Teknologi MARA (UiTM), 40450 Shah Alam, Selangor Malaysia
}

Received 24 April 2018; accepted 26 December 2018, available online 31 December 2018

\begin{abstract}
Polyurethane shape memory polymer (SMP) are comparatively low in modulus. Hence, there is a need for incorporation of chopped strand mat glass fibers as reinforcing materials for the development of SMP composites (SMPC). In this study, glass fibers in different volume fractions which are $0 \%, 5 \%, 10 \%, 15 \%$ and $30 \%$ were used. The aim is to obtain the optimum volume fractions of glass fibers in SMPC based on the dynamic mechanical properties. The dynamic mechanical analysis (DMA) was carried out to determine the dynamic mechanical properties of the composite material. The dynamic parameters which reliance to temperature such as storage modulus (E'), loss modulus (E”), damping factor $(\tan \delta)$, glass transition temperature $\left(T_{g}\right.$ ) values and others will gives the data regarding the adhesion of fiber-matrix of the composite material. The result shows that upon the addition of reinforcing fibers, an improvement in storage modulus was obtained. The $\tan \delta$ peak value were decrease when the fiber volume fractions were increased, which confirming the reinforcing effectiveness of glass fibers in SMPC. It was also observed that the $\left(\mathrm{T}_{\mathrm{g}}\right)$ increase upon the addition of reinforcing glass fibers. Summarizing, 15SMPC was chosen as the optimum volume fractions of glass fibers in SMPC. The parameter of the damping vibration demonstrates main significance for civil applications for building reliability and performance enhancement. Besides, it can foresee the impacts of temperature and time towards the polymer viscoelastic performance under various conditions. This study will provide several information to determine its functional application in future research.
\end{abstract}

Keywords: shape memory polymer, composites, volume fraction, dynamic mechanical analysis, glass fibers

\section{Introduction}

Shape memory polymers (SMP) is considered as smart materials in which it can memorized temporary shape upon applying an applicable stimulus (heat, moisture, light $\mathrm{pH}$ value) and else [1] and recover back to its original shape. SMP have several advantages and have attracted a considerable analysis interest from academia due to their potential innovative applications as actuators, temperature sensors, packaging, medical specialty devices, and damping parts [2].

There are many other available SMP but in this research, polyurethane shape memory was chosen due to its reasonable advantages when compared with the other SMP. Polyurethane SMP offers many great advantages such as low temperature flexibility, abrasion resistance, biocompatibility, and resistance to many chemicals [3]. These characteristics make polyurethane remarkably flexible material established to be fit for various application from building coatings, aviation, and biomedical application. However, their applications in structural become limited due to its comparatively low modulus and low strength of SMP [1].
Hence, the reinforcement of fibers and fillers for polyurethane which are comparatively weak has gathered several interests. The addition of reinforcement will provide significant improvement in both mechanical and thermal properties. Previous research has proven that polyurethane is a reasonable matrix for a number of reinforcing fillers including: carbon nanotubes (CNT) [4], silicon carbide [5], carbon black, silica and aluminium oxide [6] and others for the development of shape memory polymer composites (SMPC). By reinforcing polyurethane with this fibers and fillers, the utilization of SMPC might be wide.

Though, before applications of SMPC in structural, it is important to do some testing measures. This is because to incite the performance of the composite structure and behavior under occasional stress for example damping behavior [7]. Dynamic mechanical analysis (DMA) is beneficial in portraying composite structure and damping behavior dependence to frequency, temperature, time, or a combination of these parameters. [8] Besides, it also will provide information related to the physical or structural arrangement of phases such as interface, morphology and the nature of constituents $[9,10]$. 
In this study, shape memory polyurethane together with reinforced chopped strand mat glass fibers will be fabricated as composite material. Glass fibers were selected due to their excellent mechanical properties. Glass fibers will significantly increase the strength and stiffness when compared with unreinforced materials. Researchers elaborated that the presence of reinforcement have governed the dynamic mechanical properties of a composite material [11]. The aim of this present study is to obtain optimum volume fractions of glass fibers in SMPC as well as to characterize the dynamic mechanical properties of SMPC.

\section{Methodology}

\subsection{Materials}

Chopped strand mat glass fibers (EM100SH) was obtained from Nippon Electric Glass (M) Sdn. Bhd while SMP Polyurethane (MP5510) was obtained from SMP Technologies Inc, Tokyo Japan. It was supplied in two parts, which are resin (A) and hardener (B), and was processed according to manufacturer's guidelines. Table 2.1 below shows the properties of SMP Polyurethane (MP5510).

Table 2.1 Properties of SMP Polyurethane [12]

\begin{tabular}{|c|c|c|}
\hline \multicolumn{2}{|c|}{ Item } & MP 5510 \\
\hline \multicolumn{2}{|l|}{ Color tone } & $\begin{array}{l}\text { Light } \\
\text { Yellow }\end{array}$ \\
\hline \multicolumn{2}{|l|}{ A/B Weight Ratio } & $40 / 60$ \\
\hline \multirow[t]{2}{*}{ Viscosity (MPa) } & Solution A & $200-600$ \\
\hline & Solution B & $200-800$ \\
\hline \multirow[t]{3}{*}{ Specific Gravity } & Solution A & 1.062 \\
\hline & Solution B & 1.215 \\
\hline & Residue & 1.21 \\
\hline \multirow[t]{9}{*}{ Strength $\quad \mathrm{G} / \mathrm{R}$} & $\begin{array}{l}\text { Bending Strength } \\
(\mathrm{MPa})\end{array}$ & 75 \\
\hline & Bending Modulus & 1800 \\
\hline & $\begin{array}{l}\text { Tensile Strength } \\
\text { (MPa) }\end{array}$ & 52 \\
\hline & Elongation (\%) & $10-30$ \\
\hline & Hardness (Shore D) & 80 \\
\hline & $\begin{array}{l}\text { Tensile Strength } \\
(\mathrm{MPa})\end{array}$ & 20 \\
\hline & Elongation $(\%)$ & $>400$ \\
\hline & $\begin{array}{l}\text { 100\% Modulus } \\
(\mathrm{MPa})\end{array}$ & 4.5 \\
\hline & Hardness (Shore D) & 40 \\
\hline \multicolumn{2}{|c|}{ Glass Transition Point $\left({ }^{\circ} \mathrm{C}\right)$} & 55 \\
\hline \multirow[t]{2}{*}{ Cure } & Pot Life (Standard) & $180 \mathrm{sec}$ \\
\hline & $\begin{array}{l}\text { Cure Temp } \\
\left({ }^{\circ} \mathrm{C} \text { x time }\right)\end{array}$ & $\begin{array}{l}70^{\circ} \mathrm{C} \mathrm{x} \\
1 \mathrm{hr}-2 \mathrm{hr}\end{array}$ \\
\hline
\end{tabular}

\subsection{Composite Preparation}

Both chopped strand mat glass fibers and SMP Polyurethane were prepared as composite materials by using hand lay-up method. Different volume fractions of glass fibers were used in this study which are $0 \%, 5 \%$, $10 \%, 15 \%$, and $30 \%$ and are referred as pure SMP, 5SMPC, 10SMPC, 15SMPC and 30SMPC, respectively. The volume fraction $\left(\mathrm{V}_{\mathrm{f}}\right)$ of fibers were calculated based on the Equation (1) [13] below :

$$
V_{f}=\frac{W_{f} \times \rho_{f}}{\left(W_{f} \times \rho_{f}\right)+\left(W_{m} \times \rho_{m}\right)}
$$

Where $\mathrm{V}, \mathrm{W}$ and $\rho$ represents the volume, weight and density respectively, while the subscripted $f$ and $m$ represents fiber and polymer matrix, respectively.

As for the hand lay-up method, the two components, $\mathrm{A}$ and $\mathrm{B}$ are thoroughly hand-mixed for $30 \mathrm{~s}$ in the ratio of 40:60 by mass. The mixing was done slowly to prevent any excess air bubbles in the resin. The resulting reactive mixture had a pot life of about 5 minutes, so that it is necessary to pour it into the mold with chopped glass fibers immediately after mixing. An exceptional care was taken to eliminate all air bubbles possible by using hand rolling tool. A roller was used to roll and spread the mixture all around the mold surface after poured and to achieve desired thickness. It was then consequently cured for 10 minutes at room temperature and then post-cured for 4 hours at $70^{\circ} \mathrm{C}$, to give reproducible, void-free specimens with smooth surface. Finally, the specimens were cut into $35 \mathrm{~mm} \times 6 \mathrm{~mm} \times 2 \mathrm{~mm}$ for dynamic mechanical test. All the specimens were kept at room temperature prior to testing.

\subsection{Dynamic Mechanical Analysis (DMA)}

Dynamic mechanical analysis (DMA) is an effective tool for determining the morphology and viscoelastic performance behavior of the composite materials. Sample testing was performed on Dynamic Mechanical Analyzer (Mettler Toledo) (see Fig 2.1) at a fixed frequency of 1 $\mathrm{Hz}$, under a heating rate of $3^{\circ} \mathrm{C} / \mathrm{min}$, with a constant deformation of $0.1 \%$. 5 sample with different volume fractions of fibers (Pure SMP, 5SMPC, 10SMPC, 15SMPC, 30SMPC) was tested with dimension of $35 \mathrm{~mm}$ x $6 \mathrm{~mm} \times 2 \mathrm{~mm}$ each. DMA test was done in temperature range of room temperature, $25^{\circ} \mathrm{C}$ to $150^{\circ} \mathrm{C}$ by using threepoint bending mode [14]. The experimental conditions for dynamic mechanical analysis are summarized in Table 2.

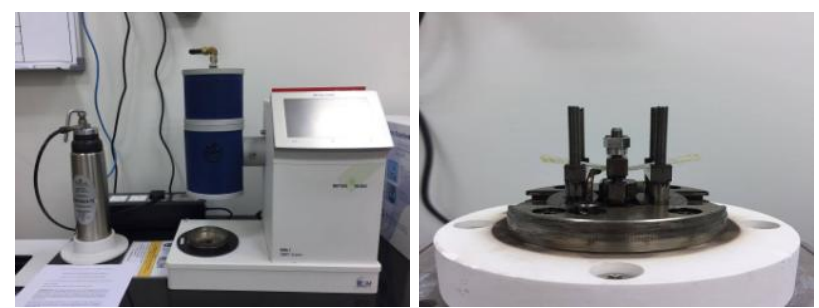

Fig 2.1 Experimental photos of DMA test and sample testing 
Table 2.2 Experimental conditions for dynamic mechanical analysis of SMPC

\begin{tabular}{ccc}
\hline Parameter & Unit & Range \\
\hline Temperature & ${ }^{\circ} \mathrm{C}$ & $25-150$ \\
\hline Heating rate & ${ }^{\circ} \mathrm{C} / \mathrm{min}$ & 3 \\
\hline Frequency & $\mathrm{Hz}$ & 1.0 \\
\hline Sample dimensions & $\mathrm{mm}$ & $6 \times 35$ \\
\hline Deformation & $\%$ & 0.1 \\
\hline Loading mode & - & Three-point bending \\
\hline Sample number & - & 5 \\
\hline
\end{tabular}

\section{Results and Discussion}

DMA has been broadly used in evaluating the performance of fibers and fillers as reinforcement in thermosetting or thermoplastic based composites. The dependence of storage modulus (E') for different volume fractions of glass fibers versus temperature were illustrated in Fig. 3.1 and Fig. 3.2 while loss modulus $(E ")$ and tan delta $(\tan \delta)$ versus temperature for different volume fractions of glass fibers were illustrated in Fig. 3.3 and Fig. 3.4.

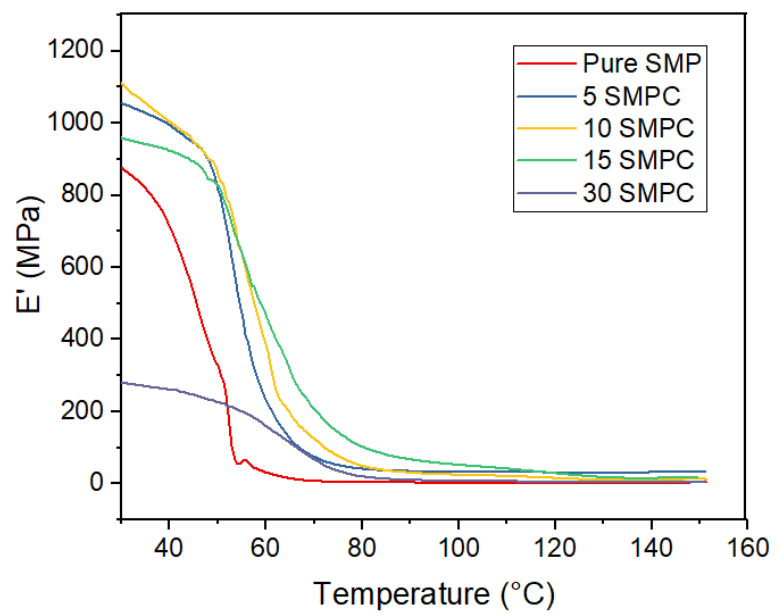

Fig. 3.1 Temperature dependence curves for storage modulus (E') for SMP composites in different volume fractions of glass fibers.

Storage modulus (E') is the measure of stored energy, representing the elastic region of the material. Based on Fig. 3.1, it is apparent that the storage modulus (E') decreases with increase in temperature. It can be related to the matrix softening which is due to the increase in movements of chain at higher temperature [15].

The $\mathrm{E}_{\mathrm{g},}, \mathrm{E}^{\prime}$ and $\mathrm{E}_{\mathrm{r}}{ }_{\mathrm{r}}$ values were taken at $30^{\circ} \mathrm{C}, 55^{\circ} \mathrm{C}$ and $120^{\circ} \mathrm{C}$, respectively. The $\mathrm{E}_{\mathrm{g}}$, values for pure SMP and SMPC are almost close to each other which indicates that at low temperatures, fibers do not have much contribution to the stiffness of the material. (See Table 3.1) [16]. From Fig. 3.2, it can be observed that higher E' values noted for SMPC when compared to Pure SMP.
This was probably because of the composition of matrixfiber that prompts to better stress transport from resin to fiber due to the improved in cross-linking density and huge amount of hydrogen bonding between the composite [18]. The effectiveness of fibers for the composites can be represented by a coefficient $C$ such as below : [16]

$$
\text { 5. } C=\frac{\left(\frac{E_{g}^{\prime}}{E^{\prime}{ }_{r}}\right)_{\text {composite }}}{\left(\frac{E_{g}^{\prime}}{E_{r}^{\prime}{ }_{r}}\right)_{r e s i n}}
$$

The lower the value of constant $\mathrm{C}$ shows high effectiveness of fibers or fillers in composite material [16]. Table 3.1 below presents the constant $\mathrm{C}$ values for different volume fractions of SMPC. In this study, the lowest value of constant $\mathrm{C}$ has been obtained for 5SMPC and 15SMPC which confirming the effectiveness of the interactions of fiber-matrix.

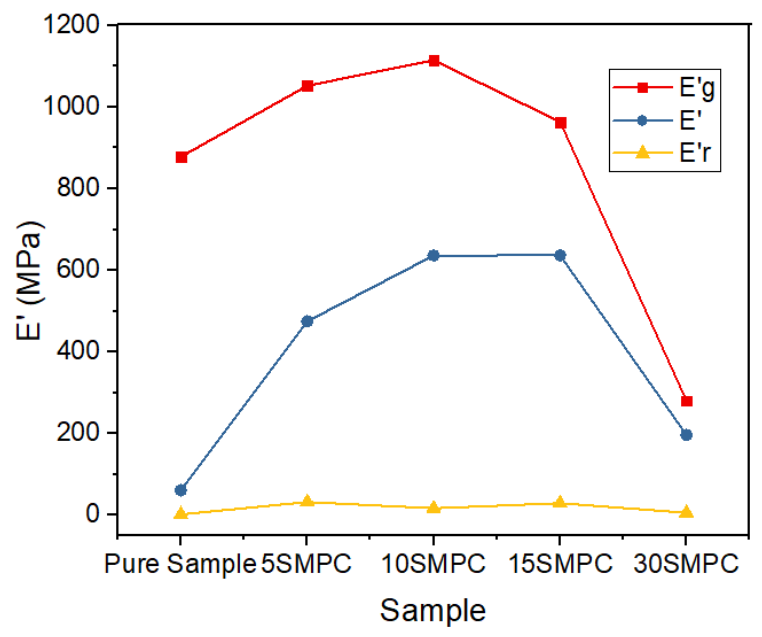

Fig. 3.2 Storage modulus (E') at different region of temperature (glassy, glass transition, rubbery) for different volume fractions of glass fibers.

Table 3.1 The value of the constant C

\begin{tabular}{ccccc}
$\begin{array}{c}\text { Sample } \\
\text { Name }\end{array}$ & $\begin{array}{c}\mathrm{E}_{\mathrm{g}}^{\prime} \\
(\mathrm{MPa})\end{array}$ & $\begin{array}{c}\mathrm{E}^{\prime} \\
(\mathrm{MPa})\end{array}$ & $\begin{array}{c}\mathrm{E}_{\mathrm{r}}^{\prime} \\
(\mathrm{MPa})\end{array}$ & $\mathrm{C}$ \\
\hline Pure SMP & 878.14 & 61.4 & 2.52 & - \\
\hline 5SMPC & 1052.5 & 475.2 & 32.88 & 0.092 \\
\hline 10SMPC & 1114.9 & 636.7 & 17.09 & 0.187 \\
\hline 15SMPC & 963.69 & 637.0 & 30.00 & 0.092 \\
\hline 30SMPC & 280.78 & 197.0 & 6.15 & 0.131 \\
\hline
\end{tabular}

Other than E', the determination of loss modulus (E") is also significant. Loss modulus (E") or dynamic loss modulus, is a viscous response of the materials and can be related to the materials tendency to dissipate energy applied to it [17]. It is also associated with "internal friction" and is subtle to different kind of motions, such as molecular chains, transitions, process of relaxation, structure of morphology and others. 


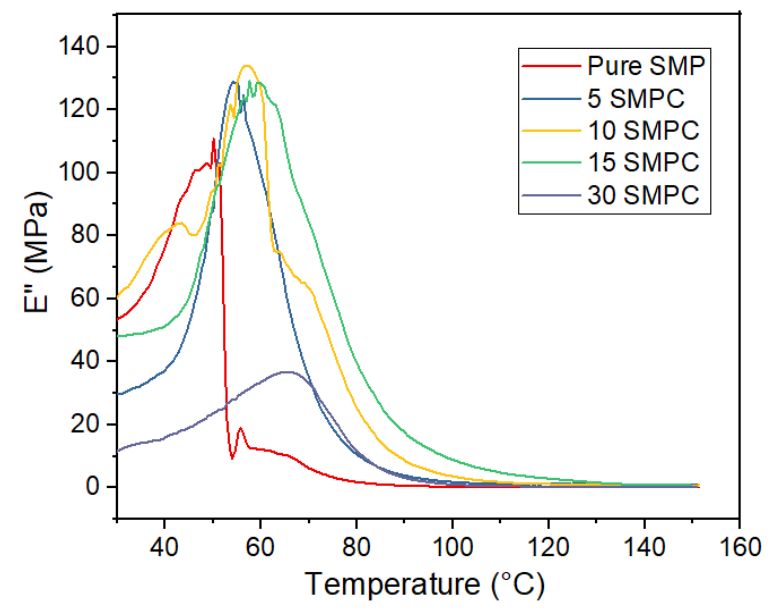

Fig. 3.3 Temperature dependence curves for loss modulus (E") for SMP composites in different volume fractions of glass fibers.

Based on Figure 3.3, it can be observed that E" decreased upon the increment of temperature. It was the same trend as E' that have been discussed previously. For E", the E" ${ }_{\mathrm{g}}$ and $\mathrm{E}_{\mathrm{r}}$ values were also taken at $30^{\circ} \mathrm{C}$ and $120^{\circ} \mathrm{C}$. (See Table 3.2). At below glass transition, it can be observed that the E peak value decrease with higher volume fractions of glass fibers while for above the glass transition temperature, the E" value increase upon higher volume fractions of fibers. Previous research also has shown the same trend of E" values [16]. Based on Table 3.2, 15SMPC have higher amount of E" for both below glass transition and above glass transition region. This shows that 15SMPC have good interfacial bonding between fiber-matrix. This is because a composite with poor interfacial bonding tends to dissipate more energy [18]. Besides, it can be observed that the width of peak for SMPC becomes broader than pure SMP. This indicates that there are relaxations of molecules in SMPC which are not present in the pure SMP. These molecular motions at the interfacial region generally contribute to the damping of the material [19].

Table 3.2 The values of loss modulus, peak height and peak width.

\begin{tabular}{ccccc}
\hline $\begin{array}{c}\text { Sample } \\
\text { Name }\end{array}$ & $\begin{array}{c}\mathrm{E}_{\mathrm{g}} \\
(\mathrm{MPa})\end{array}$ & $\begin{array}{c}\mathrm{E}_{\mathrm{r}} \\
(\mathrm{MPa})\end{array}$ & $\begin{array}{c}\text { Peak } \\
\text { height } \\
(\mathrm{cm})\end{array}$ & $\begin{array}{c}\text { Peak } \\
\text { width } \\
(\mathrm{cm})\end{array}$ \\
\hline Pure SMP & 53.37 & 0.24 & 102.67 & 14.03 \\
\hline 5SMPC & 29.61 & 1.24 & 128.47 & 16.29 \\
\hline 10SMPC & 60.75 & 1.24 & 133.90 & 30.63 \\
\hline 15SMPC & 47.92 & 2.95 & 129.20 & 26.27 \\
\hline 30SMPC & 11.87 & 0.46 & 36.77 & 20.94 \\
\hline
\end{tabular}

The ratio of loss modulus (E”) to storage modulus (E') is known as loss factor $(\tan \delta)$. The $\tan \delta$ is the study on the material changes from rigid shape to elastic shape (crystallization to rubbery phase) due to the changes in the polymer chain structures. The incorporation of fibers in a system affects the damping composite. This is principally due to the formed shear stress between matrixfibers, which reduces the additional power dissipation in the composite material [14]. Based on Fig. 3.3, it can be observed that the tan delta values for SMPC are significantly lower than pure SMP, as expected, because of the decrease of the matrix content by the presence of fiber [14]. Among these composites, 15SMPC present the lowest $\tan \delta$ peak, affirming the reinforcing effectiveness of glass fibers [20].

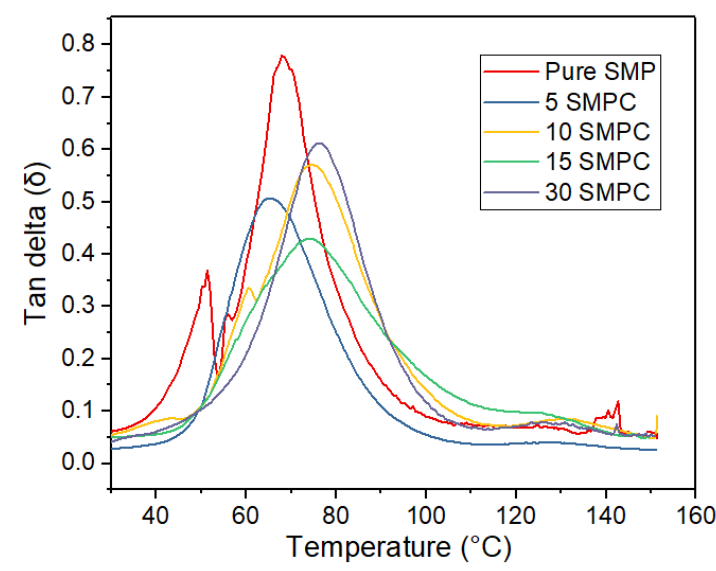

Fig. 3.4 Temperature dependence curves for tan delta for SMP composites in different volume fractions of glass fibers.

Table 3.3 The values of tan delta and Tg.

\begin{tabular}{ccc}
\hline Sample Name & Tan delta $(\delta)$ & $\mathrm{T}_{\mathrm{g}}\left({ }^{\circ} \mathrm{C}\right)$ \\
\hline Pure SMP & 0.778 & 69.06 \\
\hline 5SMPC & 0.502 & 66.88 \\
\hline 10SMPC & 0.569 & 75.59 \\
\hline 15SMPC & 0.429 & 75.71 \\
\hline 30SMPC & 0.610 & 77.25 \\
\hline
\end{tabular}

The temperature at which the $\tan \delta$ occurs is generally known as the glass transition temperature $\left(\mathrm{T}_{\mathrm{g}}\right)$ [14]. $T_{g}$ was assessed from the derivative curves of $\tan \delta$. It was observed that the $T_{g}$ of pure SMP is the lowest when compared to the other SMPC. The incorporation of fibers shifting the temperature. The shifting of $\mathrm{T}_{\mathrm{g}}$ to higher temperatures can be associated with the decreased mobility of the chains by the addition of fibers [16].

\section{Summary}

Dynamic mechanical properties of SMP containing glass fibers are significantly dependent on the volume fraction of the glass fiber. The storage modulus was enormously improved with incorporation of glass fibers. The results have shown that 15SMPC have highest storage modulus when compared to the other SMPC and it also have lowest value of $\mathrm{C}$ constant. Based on the loss modulus value, 15SMPC also shows the highest value for both region of temperature (below $\mathrm{Tg}$ and above $\mathrm{Tg}$ ) which proves that $15 \mathrm{SMPC}$ have good interface bonding 
and do not dissipate more energy when compared to the others. Besides, it also has the lowest tan delta value at 0.429 which affirming the reinforcing effectiveness of this volume fractions of glass fibers.

As the conclusion, the maximum improvement in properties is observed for composites with $15 \%$ fiber loading, which is chosen as the critical fiber loading. Summarizing, the present paper opens new possibilities of applications of shape memory polymer composites (SMPC). This is due to the reinforcement of glass fibers which enhance its functionality in terms of damping vibration properties

\section{Acknowledgements}

The authors greatly appreciated the financial supports from the research scholarship given by the Government of Malaysia and Universiti Teknologi MARA (UiTM).

\section{References}

1] Lan, X., Liu, Y., Lv, H., Wang, X., Leng, J., \& Du, S. Fiber reinforced shape-memory polymer composite and its application in a deployable hinge. Smart Materials and Structures, Volume 18, (2009), pp. 1-6.

[2] Budun, S., İşgören, E., Erdem, R., \& Yüksek, M. Morphological and mechanical analysis of electrospun shape memory polymer fibers. Applied Surface Science, Volume 380, (2015), pp. 294-300.

[3] Wu, Z., Chen, H., Huang, H., Zhao, T., Liu, X., Li, D., \& Yu, Q. A facile approach to modify polyurethane surfaces for biomaterial applications. Macromoecularl Bioscience, Volume 9, (2009), pp. 1165-1168.

[4] Xia, H., \& Song M. Preparation and characterization of polyurethane-carbon nanotube composites. Soft Matter, Volume 1, (2005), pp. 386-394.

[5] Guo, Z., Kim, T.Y., Lei, K., Pereira, T., Sugar, J.G. \& Hahn, H.T. Strengthening and thermal stabilization of polyurethane nanocomposites with silicon carbide nanoparticles by a surface-initiated-polymerization approach. Composites Science Technology, Volume 68, (2008), pp. 164-170.

[6] Benli, S., Yilmazer, U., Pekel, F., \& Özkar, S. Effect of fillers on thermal and mechanical properties of polyurethane elastomer. Journal of Applied Polymer Science, Volume 68, (1998), pp. 1057-1065.

[7] Saba, N., Jawaid, M., Alothman, Y. A., \& Paridah, M. T. A review on dynamic mechanical properties of natural fibre reinforced polymer composites. Construction and Building Materials, Volume 106, (2016), pp. 149-159.

[8] Romanzini, D., Lavoratti, A., Ornaghi Jr, H. L., Amico, S. C., \& Zattera, A. J. Influence of fiber content on the mechanical and dynamic mechanical properties of glass/ramie polymer composites, Materials and Design, Volume 47, (2013), pp. 9-15.
[9] Sreekala, M.S., \& Thomas, S. Dynamic mechanical properties of oil palm fiber/phenol formaldehyde and oil palm fiber/glass hybrid phenol formaldehyde composites. Polymer Composites, Volume 26, (2005), pp. 388-400.

[10] Jawaid, M., Abdul Khalil, \& H.P.S. Effect of layering pattern on the dynamic mechanical properties and thermal degradation of oil palm-jute fibers reinforced epoxy hybrid composite. BioResources, Volume 6, (2011), pp. 2309-2322.

[11] Jacob, M., Francis, B., Thomas, S., \& Varughese, K. T. Dynamical mechanical analysis of sisal/oil palm hybrid fiber-reinforced natural rubber composites. Polymer Composites, Volume 27, (2006), pp. 671680.

[12] Rahman, A. A., Ikeda, T., \& Senba, A. Memory effects performance of polyurethane shape memory polymer composites (SMPC) in the variation of fiber volume fractions. Fibers and Polymers, Volume 18, (2017), pp. 979-986.

[13] Gibson, R. F. Principle of Composite Material Mechanics, Fourth Edition, CRC Press, (2011).

[14] Cordeiro, E. P., Pita, V. J. R. R., \& Soares, B. G. Epoxy-fiber of peach palm trees composites: The effect of composition and fiber modification on mechanical and dynamic mechanical properties. Journal Polymer Environment, Volume 25, (2016), pp. 913-924.

[15] Joseph, P.V., Joseph, K., Thomas, S., Pillai, C. K. S., Prasad, V. S., Groeninckx, G., \& Sarkissova, M. The thermal and crystallisation studies of short sisal fibre reinforced polypropylene composites. Composites: Part A, Volume 34, (2003), pp. 253-256.

[16] Pothan, L. A., Oommen, Z., \& Thomas, S. Dynamic mechanical analysis of banana fiber reinforced polyester composites. Composites Science and Technology, Volume 63, (2003), pp. 283-293.

[17] Jawaid, M., Abdul Khalil, H. P. S., Hassan, A., Dungani, R., \& Hadiyane, A. Effect of jute fibre loading on tensile and dynamic mechanical properties of oil palm epoxy composites. Composites: Part B Eng, Volume 45, (2013), pp. 619-624.

[18] Chua, P. S. Dynamic mechanical analysis studies of the interphase. Polymer Composites, Volume 8, (1987), pp. 308-313

[19] Dong, S., \& Gauvin, R. Application of dynamic mechanical analysis for the study of the interfacial region in carbon fiber/epoxy composite materials. Polymer Composites, Volume 14, (1993), pp. 414420.

[20] Essabir, H., Elkhaoulani, A., Benmoussa, K., Bouhfid, R., Arrakhiz, F. Z., \& A. Qaiss. Dynamic mechanical thermal behaviour of doum fibers reinforced polypropylene composites. Materials and Design, Volume 51, (2013), pp. 780-788. 